\title{
SOBRE A NATUREZA DO VERBO MONOARGUMENTAL NA ORDEM V NP
}

\author{
Izete Lehmkuhl Coelho
}

RESUMO: The aim of this paper is to examine quantitatively the VNP order in monoargumental sentences of spoken Portuguese in Florianópolis. The analysis shows that the phenomenon of the NP V and VNP order does not constitute, properly, a case of variation, since types of verb (intransitive and unaccusative) and semantic roles of the NP (actor and theme) are bound to NP V and VNP order, indicating their complementarity.

PALAVRAS-CHAVE: monoargumentalidade, inacusatividade, agenteltema.

\section{INTRODUÇÃO}

$\mathrm{O}$ trabalho ora proposto pretende investigar a ordem $\mathrm{NP} \mathrm{V}$ e $\mathrm{V} \mathrm{NP}{ }^{1}$ em construções monoargumentais de 16 (dezesseis) entrevistas, extraídas do Banco VARSUL (Variação Lingüística Urbana da Região Sul) ${ }^{2}$, em especial, na variedade falada em Florianópolis, sob uma perspectiva de cunho formal. A fim de descrever os fatores condicionantes das variantes (ordem NP V e ordem V NP) tratadas neste trabalho, vamos abordar o problema sob a perspectiva que tenta conciliar a sociolingüística variacionista (cf. LABOV, 1972) com um aparato teórico da gramática gerativa (CHOMSKY, 1981, 1986), levando em conta a leitura dos dados já mediada por uma interpretação teórica.

A delimitação da monoargumentalidade teve sua origem nos trabalhos variacionistas que revelam uma correspondência entre transitividade verbal e ordem dos constituintes no português do Brasil. Trabalhos como os de Votre \&

Izete Lehmkuhl Coelho é professora da Universidade Federal de Santa Catarina.

Parte deste trabalho foi apresentada no II Congresso Nacional da ABRALIN, no período de 25 a 27 de fevereiro de 1999. Especial agradecimento às professoras Maria Cristina Figueiredo e Ana M. S. Zilles pelas valiosas sugestões.

${ }^{1}$ Vamos usar aqui o termo inglês NP (Noun Phrase) para designar sintagma nominal apenas por coerência aos outros termos por nós utilizados, tais como VP e IP.

${ }^{2}$ Os dados do Banco VARSUL serão identificados com a sigla FLP (Florianópolis), seguida do número da entrevista e do número da linha em que se encontra o exemplo. 
Naro (1984), Lira (1986, 1996), Berlinck (1988, 1995), Kato \& Tarallo (no prelo), Zilles (1999), entre outros, já revelam que a posposição do NP ao verbo no Português se associa a princípios de natureza variada que mantêm relações específicas entre si. Quanto menos transitivo um verbo é, maior a possibilidade de posposição de seu NP sujeito. Quanto mais transitivo é, menor essa possibilidade. De modo geral, a monoargumentalidade é indicada como um fator favorável à ocorrência de V NP. Entretanto, segundo Kato et alli (1996), a monoargumentalidade é uma propriedade necessária à inversão, mas não suficiente, já que nos mesmos contextos podem-se encontrar sujeitos pré-verbais. Esse é, de fato, o ponto central de nossa discussão.

A hipótese geral que pretendemos testar se refere exclusivamente à situação de estruturas V NP no interior do sistema lingüístico. Elas tentam fornecer uma melhor compreensão de duas questões: (i) qual é a natureza do verbo que permite a ordem V NP em construções monoargumentais?; (ii) qual é o papel temático do NP que se posiciona imediatamente à direita de um verbo monoargumental?

Nossa expectativa é de que haja uma correspondência entre natureza sintático-semântica do verbo e ordem dos constituintes. Enquanto uma construção intransitiva deve privilegiar construções NP V, inibindo a ordem V NP, uma construção inacusativa deve admitir mais facilmente a ordem V NP. Essas distinções podem nos levar a reafirmar a existência de pelo menos duas classes de verbos monoargumentais: a classe dos verbos intransitivos (já legitimada pela gramática tradicional) e a classe dos verbos inacusativos. A existência de uma classe de verbos inacusativos distinta da classe dos verbos intransitivos foi tratada, pela primeira vez, por Perlmutter (1976), dentro do quadro da Gramática Relacional e seguida por um certo número de autores. Entre eles, merece destaque Burzio (1986), por introduzir o conceito de inacusatividade no modelo de Princípios e Parâmetros. Ainda, do ponto de vista formal, pretendemos tratar da atribuição de papel temático ao NP selecionado por verbos inacusativos e intransitivos, valendo-nos da tipologia de Jackendoff $(1976,1987)$ sobre a composição semântica dos verbos.

$\mathrm{Na}$ tentativa de demonstrar que um estudo quantitativo pode contribuir para o tratamento formal das questões lingüísticas, pretendemos verificar se a hipótese listada acima pode ser comprovada a partir de uma análise estatística dos fatores que co-ocorrem para o fenômeno da ordem V NP, utilizando-nos do pacote VARBRUL (PINTZUK, 1988). Vale ressaltar que nossa análise pretende investigar as relações que subjazem à co-ocorrência de apenas dois grupos de fatores, dentre treze que estão sendo estudados por nós: tipo categorial do verbo e composição semântica do verbo. 


\section{A NATUREZA DO VERBO MONOARGUMENTAL}

\section{A hipótese de Burzio (1986)}

Burzio (1986, p.20) deu suporte formalista à hipótese de Perlmutter (1976), segundo a qual a classe dos verbos intransitivos não é homogênea e a heterogeneidade é estrutural. Ele parte de sentenças do italiano, uma língua de sujeito nulo, para discutir o fenômeno da inacusatividade. Considere agora algumas sentenças retomadas do autor:

\section{(1) a. Giovanni arriva \\ 'Giovanni chega' \\ b. Giovanni telefona \\ 'Giovanni telefona'}

Aparentemente essas estruturas são iguais, porém, quando os verbos chegar e telefonar recebem o clítico ne ou um auxiliar aspectual, as diferenças se acentuam:

(2) a. Ne arrivano molti

'Muitos deles chegaram'

b. *Ne telefonano molti

'Muitos deles telefonaram'

(3) a. Giovanni è arrivato

'Giovanni chegou'

b. Giovanni $h a$ telefonato

'Giovanni telefonou'

Uma das diferenças que chama a atenção nas estruturas acima é a gramaticalidade de (2a) contra a agramaticalidade de (2b). Verbos como chegar em italiano aceitam o clítico ne, ao passo que verbos como telefonar não aceitam essa espécie de cliticização. O clítico ne (ne-cl) também é possível em outros domínios, tais como, construções passivas, construções com se impessoal, construções que alteram estruturas AVB para BV (SVO/OV). Em cada um desses domínios, a cliticização do ne é uma propriedade do NP objeto quantificado, isto é, o clítico ne é usado somente com objetos, mas não com sujeitos.

Outra diferença é marcada pela seleção do auxiliar aspectual em (3), e sua exata correlação com o contraste em (2). Os argumentos de Burzio vão na direção dos de Perlmutter, segundo os quais o sujeito superficial de verbos como chegar, diferentemente do sujeito de verbos como telefonar, é um objeto direto na estrutura profunda (doravante estrutura-D). $\mathrm{O}$ autor refere-se a verbos monoargumentais que 
subcategorizam um objeto direto, como verbos ergativos ${ }^{3}$, o que significa que, para ele, o único NP subcategorizado por um verbo dessa natureza é gerado na posição de objeto, logo, à posição de sujeito não é atribuída nenhuma função temática.

Confrontando estruturas que apresentam o mesmo elemento clítico (si), como (4a) e (4b), Burzio (1986, p.37) mostra evidências de posições tematicamente marcadas e das que perderam marcação temática:
(4) a. Maria si guarda
'Maria se olha'
b. Il vetro si rompe
'O vidro se quebra'

Em (4a), o autor assume que si é um clítico reflexivo, gerado na posição de objeto, que forma cadeia com uma categoria vazia em posição de objeto, exatamente onde um clítico não reflexivo deveria estar:

(5) a . Maria si guarda [ec]

b. Maria lo guarda [ec]

Em ambos (5a) e (5b), à posição de objeto é atribuído um papel temático pelo verbo, e esse papel temático é transmitido ao clítico, via cadeia, satisfazendo assim o Princípio de Projeção. O clítico é, segundo Burzio (1986, p.38), a parte visível do Caso marcado no verbo, o Caso acusativo. A presença de ambos, Caso e papel temático, em contextos como (5), explica o fato de tais clíticos poderem se alternar com NPs lexicais, como ilustra (6):

\section{(6) a. Maria lo guarda t \\ 'Maria o olha' \\ b. Maria guarda Giovanni \\ 'Maria olha Giovanni'}

Ao contrário, o clítico si em (4b) não tem significado reflexivo e nem permite a alternância com um NP lexical, por isso deve ser considerado um afixo. Se o clítico não tem função temática, também não pode ter traço de Caso. Na verdade, a presença desse afixo é, segundo o autor, um reflexo morfológico da perda do papel temático de sujeito, como está evidente em construções transitivas do tipo (8), em contraste com (7):

\footnotetext{
${ }^{3}$ A terminologia correspondente na Gramática Relacional difere da de Burzio. Para a classe dos verbos inacusativos o autor usa o termo ergativo a para a classe dos verbos inergativos, o termo intransitivo. Neste trabalho, preferimos usar a nomenclatura inacusativo e intransitivo, respectivamente.
} 
(7) a. Il vetro si rompe

b. * Il vetro rompe Giovanni

'O vidro quebra Giovanni'

(8) Maria rompe il vetro

'Maria quebra o vidro'

A alternância entre NP realizado como sujeito e o clítico si marca a derivação de construções inacusativas a partir de transitivas, semelhantes aos pares AVB/BV.

Embora em uma língua como o português o teste sintático referente à cliticização do ne e à seleção diferenciada dos auxiliares aspectuais não esteja disponível, como no italiano, algumas semelhanças de comportamento entre as duas línguas podem dar indícios de que o fenômeno da inacusatividade é um fenômeno universal. As construções com o clítico se, as construções passivas, as construções BV (do contraste entre AVB/BV), as construções existenciais e as construções com verbos do tipo aparecer e chegar são exemplos dessa possibilidade. Vejamos.

Em relação a estruturas com o elemento clítico, evidências do português mostram que, com verbos como quebrar, o clítico mais se parece com um afixo, enquanto em estruturas com verbos do tipo de vestir, o clítico reflexivo pode se alternar tanto com um clítico não-reflexivo quanto com um NP lexical, à semelhança do italiano:

\footnotetext{
(9) a. O copo se quebrou t

b. * O copo $a$ quebrou $t$

c. * $\mathrm{O}$ copo quebrou a menina
}

\section{(10) a. Maria se vestiu $\mathrm{t}$ \\ b. Maria $a$ vestiu $t$ \\ c. Maria vestiu a menina}

Se em (9) tivéssemos A menina quebrou o copo, a sentença seria gramatical, mostrando que a alternância do clítico se com um NP lexical realizado como sujeito (com traços de animacidade) marca, na verdade, que o clítico é um reflexo morfológico da perda do papel temático do sujeito A menina, derivando sentenças inacusativas a partir de transitivas (pares AVB/BV). Estudos mostram que o clítico não-reflexivo no português já está desaparecendo, tornando-se bastante possível (e talvez muito mais recorrente) sentenças como (11a). Entretanto, o clítico reflexivo não pode estar ausente, como a agramaticalidade de (11b) confirma:

(11) a. $O$ copo quebrou b. * A menina vestiu 
É importante salientar que a sentença em (11b) só seria gramatical se o argumento interno estivesse nulo. ${ }^{4}$

Como a função temática do argumento externo $A$ menina em (12a) realiza o papel temático de agente, parece natural dizermos que a ausência do clítico em (12d) evidencia a perda do sintagma que tem a função temática de agente (ou a de experienciador, por exemplo) e que a alternância de estruturas AVB/BV é um processo dessa natureza, como o paradigma abaixo confirma:

(12) a. A menina quebrou o copo com o martelo

b. * $O$ copo quebrou o martelo

c. $O$ copo se quebrou

d. $O$ copo quebrou

Em (12), podemos observar que enquanto o verbo de uma construção transitiva seleciona um argumento externo e um argumento interno necessariamente, o verbo de uma construção inacusativa seleciona apenas um argumento interno, argumento que, no dizer de Jackendoff (1976), reflete a função temática de tema. Essas restrições selecionais, que permitem estabelecer diferenças entre os pares $\mathrm{AVB} / \mathrm{BV}$, também podem justificar a divisão dos verbos monoargumentais em duas classes autônomas.

Outro argumento de Burzio $(1981,1986)$ a respeito do critério de inacusatividade, a propriedade de não atribuir Caso acusativo ao NP objeto de um verbo inacusativo, fundamenta-se nas explicações de Chomsky (1981) em relação às construções passivas. A morfologia passiva, segundo Chomsky, tem a propriedade de bloquear a atribuição da função temática externa à posição de especificador de VP. Além de não projetar uma função temática externa, o verbo passivo, devido a sua morfologia específica, perde a capacidade de atribuir Caso acusativo. Com base nessas duas propriedades da construção passiva, e observando que as construções com verbos como chegar manifestam efeitos semelhantes aos da passiva, Burzio propõe a seguinte generalização 'um verbo atribui função temática externa se e somente se atribui Caso acusativo', formalizando o que fica sendo conhecida na literatura como a generalização de Burzio.

A generalização de Burzio explica as diferenças entre os verbos intransitivos e inacusativos e implica dizer que os verbos intransitivos, assim como os verbos transitivos, têm a capacidade de atribuir Caso acusativo (mesmo que seja um objeto cognato), contrariamente aos verbos inacusativos. Essa proposta de inclusão de uma classe de verbos inacusativos à tradição gramatical assenta-se, portanto, em uma correlação entre a não-atribuição de papel temático à posição externa a V', e a não-atribuição de Caso acusativo ao NP em posição de objeto. Isso significa que as estruturas inacusativas diferem das estruturas intransitivas em

${ }^{4}$ Vale ressaltar, porém, que Assis (1988) encontrou, em um dialeto rural do alto-médio São Francisco MG, sentenças como (11b) sem clítico reflexivo. Agradeço à Ana Zilles por essa observação. 
dois pontos: (1) só exibem como posição temática a posição interna a V; (2) ao NP dessa posição interna não é atribuído Caso acusativo (grifos nossos) ${ }^{5}$.

As evidências sintáticas verificadas no português mostram que os verbos monoargumentais são de natureza diferente, servindo de base teórica para levantar o fator tipo categorial do verbo. Nossa hipótese, que se relaciona exclusivamente ao componente interno da língua, é de que a monoargumentalidade não é condição suficiente e necessária à posposição; as diferenças entre verbos inacusativos e intransitivos devem estar refletidas também na ordem dos constituintes.

\section{A hipótese de Jackendoff $(1976,1987)$}

Jackendoff (1976) propõe uma teoria das representações semânticas que dê conta das condições de boa formação de uma sentença. Ela deve explicar não somente por que a informação é conduzida à sentença, mas também deve explicar o modo como essa informação é conduzida, permitindo a expressão de ambas as generalizações sintática e semântica da língua. Nessa teoria, o autor apresenta uma tipologia verbal com cinco noções básicas, relacionadas aos verbos (ou predicados abstratos) de movimento, pontuais ou de localização, durativos, agentivos causativos e agentivos permissivos, que será sumarizada a seguir.

As noções de movimento são representadas através da função semântica $\mathrm{GO}(\mathrm{x}, \mathrm{y}, \mathrm{z})$. Esta função descreve um evento que compreende o movimento de alguma entidade $x$, que muda sua localização física (ou abstrata): um movimento que vai de $y$ a $z$. No exemplo (13), abaixo, $x$ corresponde ao tema ( $O$ trem), $y$ à origem (Curitiba) e $z$ à meta (Porto Alegre):

\section{(13) O trem viajou (de Curitiba a Porto Alegre)}

O tema ocorre na posição de sujeito; a origem, como objeto da preposição de e a meta, como objeto da preposição a (ou dentro). Podemos encontrar, ainda, exemplos em que ou a origem ou a meta ou ambos não estão especificados. Além disso, nem sempre a origem é o objeto da preposição de ou a meta é o objeto da preposição a. Em $O$ trem deixou Curitiba, a origem aparece como objeto direto. Já em João pôs o balde no poço, o sujeito não é nem tema, nem origem ou meta, mas agente, o objeto direto é o tema e a meta é o objeto da preposição em. Nesse último caso, a função semântica não é mais a de GO, mas a de CAUSE, por introduzir na composição do verbo a noção de FAZER alguma coisa; essa função será discutida posteriormente.

As noções de localização não descrevem um movimento, mas a localização de um objeto relativo a um outro objeto. O NP que descreve o objeto

\footnotetext{
${ }^{5}$ As questões relativas `a atribuição de Caso ao NP pós-verbal não serão tratadas neste trabalho. Veja os questionamentos de Belletti (1988) e Koopman \& Sportiche (1988) à hipótese de atribuição de Caso por Cadeia de Burzio (1986).
} 
cuja localização está especificada é o tema e o NP que descreve o objeto em termos do qual a posição do tema é especificada é o locativo. A representação semântica formal desta função é: $\mathrm{BE}(\mathrm{x}, \mathrm{y})$, onde $x$ é o tema e $y$ é o locativo.

Considerem-se os exemplos em (14):

(14) a. O cachorro está à esquerda do gato

b. O cachorro moveu-se para a esquerda do gato

Enquanto (14a) equivale a uma configuração espacial particular, a um state of affair, um objeto $x$ ( $O$ cachorro) localizado em termos de um objeto y (o gato); (14b) equivale a um evento que indica movimento: $x$ é um tema que se move de algum lugar não especificado $y$ para um lugar especificado $z$, à esquerda do gato. Logo, (14a) descreve a função BE e (14b), a função GO.

Uma outra noção importante discutida por Jackendoff é a de duração, que pode ser descrita através da função semântica STAY (x,y), onde $x$ é o argumento que corresponde ao tema e $y$ o argumento que corresponde ao locativo. Esses verbos aceitam advérbios durativos, mas não advérbios pontuais (cf. (15)).

(15)a. O cachorro permaneceu à esquerda do gato

b. (Por duas horas) $\mathrm{O}$ cachorro permaneceu à esquerda do gato

A função STAY difere da função BE porque ela é formada por verbos que se referem a situações que podem acontecer em uma extensão temporal, enquanto a função $\mathrm{BE}$ é formada por verbos que se referem a situações pontuais. Há alguns testes propostos pelo autor - e que já são conhecidos na literatura - para diferenciálas. Enquanto (15) pode ser usado como uma resposta à pergunta: $O$ que aconteceu?, (14a) não é gramatical como resposta a esta mesma pergunta, como podemos observar em (16), abaixo:

gato]

(16) a $O$ que aconteceu foi que [o cachorro permaneceu à esquerda do

$$
\text { b. O que aconteceu foi que [*o cachorro está à esquerda do gato] }
$$

Verbos da função BE não respondem a essa pergunta porque são verbos que descrevem um estado. Esse tipo de verbo é definido negativamente como aquele que não é marcado por propriedades aspectuais de duração e nem de movimento. Verbos de duração (tipo STAY) descrevem eventos e nesse sentido são como os verbos do tipo $\mathrm{GO}$, fornecem resposta gramatical para a pergunta $O$ que aconteceu?: direita]

(17) O que aconteceu foi que [o cachorro se moveu da esquerda para a 
É importante ressaltar que os verbos do tipo STAY descrevem a permanência de um estado e os do tipo GO, mudanças de estado ou posição. Entretanto, ambos são verbos de evento que descrevem um processo.

O tema é o elemento principal dessas três funções não-agentivas. Com verbos de estado, o tema é o objeto que está em algum lugar; com verbos de duração, é o objeto que permanece em algum lugar e com verbos de movimento, é o que quer que tenha se movido.

A função semântica de agente, discutida por Jackendoff (1976), é representada pelas noções de causa e de permissão: CAUSE (x, e) e LET (x, e). Verbos do tipo CAUSE e LET respondem à pergunta $O$ que aconteceu? e, além disso, à pergunta $O$ que o NP fez?, porque descrevem uma ação. Como a idéia de evento é mais abrangente do que a idéia de ação, porque permite como resposta verbos processuais ou agentivos, podemos dizer que verbos que manifestam a abstração do FAZER (DO) descrevem um evento agentivo. Entretanto, um dos problemas dessa tipologia é o de forçar uma leitura causativa de todo verbo de ação que não seja de permissão, o que deixa de fora certas construções, como por exemplo, as prototipicamente intransitivas e as passivas.

Tal problema, porém, parece resolvido no trabalho de 1987, quando o autor discute alguns conceitos tratados em 1976 e amplia as funções semânticas, introduzindo mais uma função agentiva, a função $\operatorname{ACT}(\mathrm{x}, \mathrm{y})$, onde $x$ é o agente e $y$ ocorre como um argumento paciente opcional. A função ACT estaria completando as funções agentivas não-causativas e nem permissivas, resolvendo o problema descrito acima. Novamente o autor sugere testes que possam caracterizar um argumento agente, do mesmo modo que no trabalho anterior.

Um outro ponto importante discutido por Jackendoff (1987) diz respeito ao estatuto do critério temático formulado por Chomsky (1981). A correspondência biunívoca entre posição argumental e papel temático é criticada pelo autor, que tenta mostrar casos em que um NP tem mais do que um papel temático, como os exemplos em (18) ilustram.

reitor

(18) a. A encomenda saiu (*deliberadamente) muito cedo do gabinete do

b. João saiu (deliberadamente) muito cedo do gabinete do reitor

Se a presença do advérbio deliberadamente for gramatical, o NP João em (18b) é, no dizer de Jackendoff (1976), ao mesmo tempo agente, por exercer a ação de sair, e tema, por indicar o objeto (no caso específico, o corpo) que sai. Em nossa análise, entretanto, apesar de, a princípio, admitirmos que verbos como sair ora podem se manifestar como um verbo processual (cf. (18a)), ora como um verbo de ação (cf. (18b)), não assumiremos a proposta de duas (ou mais) funções sobrepostas ao mesmo sintagma, já que partimos do pressuposto chomskiano de que a cada papel temático corresponde exatamente uma posição argumental e que cada posição argumental é expressa por um e somente um papel temático (grifos 
nossos). Temos, portanto, que tentar explicar a derivação de (18) com verbos do tipo de sair, dada a possibilidade combinatória entre os verbos e os argumentos por eles selecionados. Vale ressaltar, nesse momento, que para o autor papéis temáticos são fruto da composicionalidade dos itens lexicais que constituem uma sentença. Essa proposta será retomada no item subseqüente.

Uma vez estabelecidas as especificidades que cada um dos tipos de verbos, acima arrolados, apresenta com seus argumentos do ponto de vista sintático-semântico, pretendemos investigar nos dados empíricos se o fator natureza do verbo vai determinar a ordem V NP em uma língua como o português, evidenciando a possibilidade de co-ocorrência entre os fatores tipo categorial do verbo e sua composição semântica. Nossa expectativa é de que verbos do tipo BE, STAY e GO vão favorecer a ordem V NP por manifestarem uma função nãoagentiva, enquanto verbos do tipo ACT vão privilegiar a ordem NP V por descreverem um evento agentivo.

\section{DESCRIÇÃO E ANÁLISE DOS RESULTADOS}

\section{A composição semântica dos verbos}

Para a discussão da variável composição semântica dos verbos monoargumentais - o primeiro grupo de fatores a ser selecionado pelo programa estatístico VARBRUL - tomamos a tipologia de Jackendoff (1976, 1987) como base. Segundo essa tipologia, a categoria estado compreende verbos do tipo BE existencial $^{6}$ que se manifestam em um determinado tempo e espaço. A categoria evento compreende dois tipos de verbos: verbos de ação, do tipo ACT; e verbos de mudança de estado ou permanência de um estado em um determinado tempo e espaço; esses últimos estão aqui representados por verbos do tipo GO, $\mathrm{APPEAR}^{7}$ e STAY.

Os percentuais obtidos pela quantificação de 2033 sentenças declarativas são relevantes. É notável a correlação entre ordem dos constituintes e o grupo de fatores composição semântica do verbo, como a Fig. 1 ressalta, abaixo:

\footnotetext{
${ }^{6}$ Separamos os verbos do tipo BE locativo dos verbos do tipo BE existencial e observamos que diferentemente de $\mathrm{BE}$ existencial, verbos do tipo $\mathrm{BE}$ locativo apresentaram contextos categóricos de ordem NP V, por isso foram deixados de fora desta nossa análise.

${ }^{7}$ Resolvemos separar do conjunto dos verbos do tipo GO, verbos do tipo APPEAR por estarem representando movimento abstrato, tais como aparecer, surgir, nascer, morrer, etc, diferentemente de verbos que representam movimento concreto (do tipo GO), como chegar, sair, entrar, etc
} 
Freqüência e probabilidade de V NP, segundo o grupo de fatores composição semântica do verbo

\begin{tabular}{|c|c|c|c|}
\hline Composição semântica do verbo & Apl./Total & $\%$ & P.R. \\
\hline Verbos do tipo ACT & $18 / 524$ & 03 & .23 \\
\hline Verbos do tipo STAY & $05 / 58$ & 09 & .47 \\
\hline Verbos do tipo GO & $110 / 692$ & 16 & .53 \\
\hline Verbos do tipo APPEAR & $131 / 360$ & 36 & .70 \\
\hline Verbos do tipo BE existencial & $378 / 399$ & 95 & .93 \\
\hline Total & $642 / 2033$ & 32 & \\
\hline
\end{tabular}

Fig.1

Podemos observar na Fig.1 uma correspondência direta entre percentuais e probabilidade - a curva ascendente é a mesma - de verbos do tipo ACT inibidores da ordem V NP a verbos do tipo BE existencial, quase categóricos nessa ordem. Quanto aos verbos do tipo STAY, GO e APPEAR, observa-se tanto na freqüência quanto na probabilidade uma maior variabilidade: ordem NP V e ordem V NP, apontando entre eles um aumento gradativo de V NP: 09\%, 16\% e 36\%, respectivamente. Vale lembrar que tais verbos, segundo Jackendoff (1976), representam funções semânticas que, na grande maioria das vezes, manifestam uma entidade $x$ que realiza o papel temático de tema. Em sendo assim, esperaríamos que fossem contextos favorecedores de V NP.

Tomemos, em primeiro lugar, os verbos do tipo STAY para análise. Um rastreamento nas ocorrências pôde nos explicar o percentual de apenas $9 \%$ de V NP. O fato de $67 \%(39 / 58)$ dessas estruturas estarem formadas por pronomes pessoais e/ou pronome 'a gente', como os exemplos em (19) ilustram.

(19) a. A gente tinha que estar na estrada (FLP18L677)

b. Ela teve um mês e pouco no hospital (FLP03L1108)

Tais pronomes determinam a ordem NP V, como a literatura já observou (cf. LIRA (1986, 1996), Berlinck (1988, 1995) e Zilles (1999). Por esse motivo, tais contextos vão ser deixados de fora da análise, nesse primeiro momento.

Com relação aos verbos do tipo GO e APPEAR, os resultados da tabela indicam um caso mais típico de variação, apontando um percentual e uma probabilidade mais significativos de V NP, principalmente para os do tipo APPEAR. Vamos discutir um pouco essa diferença. Verbos do tipo GO descrevem um movimento concreto, representado, principalmente, por um NP tema que se move de um lugar para outro. Esta função manifesta a categoria semântica de evento justamente porque esse movimento descreve na grande maioria das vezes mudanças de estado: a entidade $x$ vai de um estado $y$ para um estado $z$. Comparemos então essa função com a do tipo APPEAR, que também descreve mudanças de estado. Observem-se os exemplos abaixo:

(20) a. O processo vai de um gabinete a outro sem solução

b. O processo apareceu no gabinete do Reitor 
No exemplo (20a), o modo de localização do movimento é o de posição, um movimento mais concreto, isto é, o NP O processo vai de um gabinete para outro. Já em (20b), o modo de localização é o de identificação do NP, quer dizer, $O$ processo surge (é identificado) em algum lugar. Essa diferença parece importante com respeito à ordem dos constituintes, basta que verifiquemos os índices percentuais e probabilísticos entre as construções do tipo GO e APPEAR na ordem V NP, descritos na Fig.1. E a pergunta que levantamos é a seguinte: por que verbos do tipo GO tornam menos provável a ocorrência de seus argumentos a sua direita, em relação a verbos do tipo APPEAR?.

Para tentar responder a essa pergunta, tomamos os verbos do tipo GO para reanálise. Verbos que descrevem mudança de estado concreta, isto é, quando a posição de um objeto muda de um lugar para outro, parece admitirem além da categoria de evento uma categoria de ação, o que resultaria em pelo menos duas funções semânticas diferenciadas, como o exemplo (18) da seção anterior já ilustrou.

Considerem-se agora os exemplos em (21) e (22), extraídos de nossos dados de fala, para efetuarmos alguns testes propostos por Jackendoff para o reconhecimento dessa diferença:

(21) a. A gente ia na missa, e da missa a gente ia pra casa (FLP08L.275) (FLP18L.668)

b. nesse ônibus, o que é que ia? Ia galinha, ia porquinho, ia pinto

(22) a. E chegava meia noite, o homem saía, se vestia de lobisomem (FLP08L.470) variados

b. Sai galinha frita, sai galinha assada de forno também, sempre uns pratos

(FLP08L152)

Tanto as construções em (21) como em (22) são eventos por permitirem resposta à pergunta $O$ que aconteceu?, entretanto, só (21a) e (22a) admitem respostas à questão $O$ que o $N P$ fez?. Logo, são manifestações de um evento [+agentivo], enquanto (21b) e (22b) são eventos processuais.

A diferença entre $(21 a) /(22 a)$ e $(21 b) /(22 b)$ também pode ser reforçada pela possibilidade (ou não) de uso de advérbios do tipo deliberadamente e intencionalmente, tal como (23) e (24) ilustram:

(23) a. A gente ia deliberadamente/intencionalmente na missa

b. *Ia galinha deliberadamente/intencionalmente, ia porquinho, ia pinto

(24) a. O homem saía deliberadamente/intencionalmente, se vestia de lobisomem 
b. *Sai galinha frita deliberadamente/intencionalmente, sai galinha assada de forno também

A possibilidade de uso de tais advérbios vem ressaltar o fato de o sujeito em (23a) e (24a) ser o controlador da ação, ele é responsável 'intencionalmente' pelo ato de ir e de sair de algum lugar, mesmo que não o seja pelas suas conseqüências (não está em questão aqui a função semântica do tipo CAUSE). Já em (23b) e (24b) o sujeito não exerce o controle de nenhuma atividade.

Além das diferenças de cunho semântico, vale a pena mencionar diferenças sintáticas como a ordem dos constituintes na sentença. (21a) e (22a) apresentam a ordem direta e (21b) e (22b) a ordem inversa. Se as primeiras fossem alteradas para a ordem inversa e se as últimas fossem alteradas para a ordem direta, as sentenças se degradariam sensivelmente:

(25) a. *Ia a gente na missa e da missa a gente ia pra casa ${ }^{8}$

b. nesse ônibus, o que é que ia? * galinha ia ...

(26) a. *E chegava meia noite, saía o homem, se vestia de lobisomem? b. *Galinha frita sai, sai galinha assada de forno também

Figueiredo Silva (1996, p.102) já ressaltou que existe um contraste claro em relação à ordem dos constituintes entre (27a) e (27b), retomados do exemplo (30) da autora:

(27) a. Saiu a renovação da minha bolsa

b. * Saiu João

O problema é que esse contraste nos forçaria a postular duas entradas lexicais para o mesmo verbo sair, ou, quem sabe, a possibilidade de estipular a transitivização de certos verbos, seguindo a proposta de Whitaker (1989). Tais observações de Figueiredo Silva são colocadas apenas como ponto de partida para uma discussão mais cuidadosa a respeito, segundo ela mesma confere, com a preocupação apenas de sublinhar a existência de tal processo.

As diferenças de gramaticalidade, apontadas nos exemplos (23)-(27), são evidências fortes para se considerar que verbos de movimento podem manifestar pelo menos duas funções semânticas, em uma língua como o português: uma função [-agentiva] e uma função [+agentiva]. Essas funções foram reanalisadas

\footnotetext{
${ }^{8}$ Esta sentença só seria boa se o primeiro sintagma $a$ gente estivesse focalizado

${ }^{9}$ Contextos de posposição se adaptariam melhor a sintagmas [-definidos] como em (i):

(i) E chegava meia noite, saíam homens que se vestiam de lobisomem.

Vale ressaltar que em (i) o sintagma homens ao estar posposto perde traços de agentividade.
} 
como funções do tipo GO [-ação] e GO [+ação], respectivamente. Observemos os resultados estatísticos da Fig.2:

Reanálise da freqüência de V NP, segundo a possibilidade de o verbo GO admitir NPs [+agentivos] e NPS [-agentivos]

\begin{tabular}{|c|c|c|}
\hline Composição semântica dos verbos de movimento & Apl./Total & $\%$ \\
\hline Verbos do tipo GO [-ação] & $102 / 193$ & 52 \\
\hline Verbos do tipo G0 [+ação] & $08 / 499$ & 01 \\
\hline
\end{tabular}

Fig.2

Vale lembrar aqui de algumas explicações dadas na literatura para as diferenças de papel temático que o sujeito recebe em sentenças como (28):

\section{(28) a. João quebrou a perna \\ b. João quebrou o vaso}

O sentido de cada uma das sentenças em (28) é dado pela composição do verbo com o complemento: em (28a) o sintagma João é o paciente (ou o objeto afetado) do evento quebrou uma perna, enquanto em (28b) é o agente de quebrou o vaso. Essa diferença de sentido já foi tratada por Chomsky (1986), quando adota o ponto de vista segundo o qual o papel temático do argumento externo não é determinado pelo verbo sozinho, mas é composicionalmente determinado pelo complexo verbocomplemento. A composicionalidade talvez possa explicar, também, as diferenças apontadas acima para verbos monoargumentais do tipo GO. Discutiremos essa possibilidade no item subseqüente.

\section{O fenômeno da inacusatividade}

Como já discutimos em trabalhos anteriores (COELHO,1998,1999), a inacusatividade da construção propicia uma maior liberdade de ordenação de seu argumento nuclear, enquanto diminui a variação à medida que os contextos passam a ser relativamente "mais transitivos" (construções intransitivas). É o mesmo que os percentuais de freqüência do grupo de fatores tipo categorial do verbo ${ }^{10}$ estão mostrando na Fig. 3, a partir de uma distinção bastante geral entre verbos intransitivos e verbos inacusativos:

\footnotetext{
${ }^{10}$ Vale ressaltar que os grupos de fatores composição semântica do verbo e tipo categorial se sobrepuseram em todas as rodadas estatísticas do VARBRUL. Quando os dois coexistiam o grupo composição semântica era selecionado sempre em primeiro lugar, enquanto o grupo tipo categorial não era sequer selecionado. Quando, porém, o grupo composição semântica era eliminado da rodada, o grupo tipo categorial era selecionado, só que na ordem de seleção não era o primeiro em termos de importância, mas o terceiro, o que significa que o grupo de fatores composição semântica do verbo, neste momento, foi explanatoriamente mais forte que o outro.
} 
Freqüência de V NP, segundo o grupo de fatores tipo categorial do verbo (Florianópolis, VARSUL)

\begin{tabular}{|c|c|c|}
\hline Tipo categorial do verbo & Apl/Total & $\%$ \\
\hline Verbos intransitivos & $18 / 524$ & 03 \\
\hline Verbos inacusativos & $624 / 1509$ & 41 \\
\hline Total & $642 / 2033$ & 32 \\
\hline \multicolumn{2}{|c}{ Fig.3 }
\end{tabular}

Os resultados acima rediscutem os trabalhos que apontam o ambiente da monoargumentalidade como um ambiente propício à posposição, e, em conseqüência, a uma redefinição da classe dos verbos monoargumentais. Como evidências favoráveis à nossa hipótese, verbos inacusativos apresentam ambientes mais propícios à ordem V NP $(41 \%)$ do que verbos intransitivos $(03 \%)$.

Nosso intuito agora é tentar definir melhor quais os contextos inacusativos que mais se adaptam à ordem V NP. Comparando os resultados da Fig.2 com os da Fig.3, observemos que deve haver uma correspondência direta entre verbos do tipo GO, APPEAR, STAY ou BE existencial e os verbos inacusativos e verbos do tipo ACT e os verbos intransitivos; efetuamos, então, uma reanálise dos grupos de fatores em questão. Os resultados dessa reanálise podem ser vistos na Fig.4, abaixo.

Freqüência e probabilidade de $\mathrm{V} N \mathrm{P}$, segundo a reanálise entre os

grupos de fatores composição semântica e tipo categorial do verbo (Florianópolis, VARSUL)

\begin{tabular}{|c|c|c|c|c|}
\hline \multicolumn{2}{|c|}{$\begin{array}{c}\text { Reanálise dos grupos de fatores tipo categorial e composição } \\
\text { semântica do verbo }\end{array}$} & Apl./Total & $\%$ & P.R. \\
\hline Verbo intransitivo & Verbos do tipo ACT & $18 / 524$ & 03 & .18 \\
\hline \multirow{3}{*}{ Verbo inacusativo } & Verbos do tipo GO [+ação] & $08 / 499$ & 01 & .13 \\
& Verbos do tipo STAY & $05 / 58$ & 09 & .47 \\
& Verbos do tipo APPEAR & $131 / 360$ & 36 & .70 \\
& Verbos do tipo GO [-ação] & $102 / 193$ & 52 & .78 \\
& Verbos do tipo BE existencial & $378 / 399$ & 95 & .97 \\
\hline
\end{tabular}

Fig.4

Considerando a relação inerente que o grupo de fatores composição semântica do verbo guarda com tipo categorial do verbo, a associação desses dois grupos de fatores não constitui contradição. Pelo contrário, os percentuais obtidos pela reanálise dos dois grupos de fatores é relevante. É notável a correlação entre natureza do verbo e ordem V NP em termos de freqüência e de probabilidade: há uma associação entre as construções intransitivas com função semântica ACT e a ordem NP V; inversamente, a ordem V NP se restringe a contextos monoargumentais de construções inacusativas com função semântica GO [-ação], APPEAR, STAY e BE existencial.

Todavia, admitindo que o papel temático é uma condição da estrutura-D no modelo de Princípios e Parâmetros, podemos questionar os resultados relativos aos verbos inacusativos do tipo GO, já que contemplam também verbos que 
selecionam argumentos [+agentivo]. Como podemos observar na Fig.4, os verbos da função $\mathrm{GO}$ [+ação] mais se aproximam dos verbos do tipo ACT com relação à ordem dos constituintes, a saber, descrevem contextos que inibem a ordem V NP, talvez por isso o percentual geral de V NP na Fig.3 não seja tão significativo assim. Precisamos, então, encontrar uma maneira de explicar como os verbos do tipo GO podem selecionar argumentos diferenciados do ponto de vista do papel temático que atribuem sem que para isso precisemos dizer que deve haver duas entradas lexicais para verbos dessa natureza.

Um grande problema a tratar é o fato de geralmente relacionarmos um predicado inacusativo à impossibilidade de selecionar argumentos [+agentivos]. Se assim fosse, teríamos de dizer que verbos do tipo GO [-ação] e do tipo GO [+ação] teriam duas entradas lexicais, mas a teoria que estamos utilizando aqui não permite uma classificação dessa natureza. De mais a mais, o componente lexical "incharia" muito se, para cada interpretação diferenciada, tivéssemos de admitir uma outra entrada, o que de fato não estaria em conformidade com a tendência cada vez mais econômica e regular da teoria.

Vale lembrar que nossa discussão sobre agentividade está pautada nas considerações de Jackendoff (1976), segundo as quais sintagmas realizam papéis temáticos de agente quando apresentam traços de volitividade, ou seja, são instigadores extrínsecos do evento. Nessa proposta do autor, alguns pontos são considerados essenciais para o reconhecimento desses traços: a possibilidade de construções admitirem respostas a perguntas do tipo $O$ que (foi que) o DP fez?; a possibilidade de permitirem advérbios marcados por traços [+volitivo] e a necessidade de o sintagma nominal estar representado por um DP [+animado $]^{11}$, em especial, [+humano] para realizar-se como [+agentivo], como os critérios de gramaticalidade acima já apontaram. Acrescida a essas propriedades, a ordem parece exercer um papel fundamental na definição de um sintagma [+agentivo] no português.

É possível que haja algum tipo de restrição na gramática que exija que um sintagma [+agente], argumento de um verbo monoargumental, precise se alçar para a posição marcada por Caso nominativo, independentemente do tipo de construção, em oposição ao que acontece com um DP que realiza o papel de tema. Talvez seja possível dizer que existe aí uma distribuição complementar: a posição de sujeito (posição de especificador de IP) deve ser o lugar em que se realiza o papel de agente e a posição de especificador de VP, o lugar em que se realiza o papel de tema. A ordem do sintagma que se realiza como tema, no entanto, é variável quando não há sintagma agente na construção que possa ocupar a posição de sujeito.

\footnotetext{
${ }^{11}$ Estamos considerando aqui que verbos que realizam o papel de agente só selecionam argumentos [animados] metonimicamente, como em:
}

(i) Aí o Instituto de Educação desfilava em peso (FLP24L760) 
Vamos supor, então, que a construção da inacusatividade se dá a partir de entradas lexicais marcadas pelas categorias de evento e de estado, localizandoas em um tempo e um espaço; enquanto a construção da intransitividade também se dá pela categoria evento, porém, sem estar localizada em um tempo e um espaço. A categoria evento deveria ser subespecificada pela categoria [+/-ação], já que partimos da proposta de Jackendoff, segundo a qual sentenças que expressam ação devem ser consideradas um subconjunto daquelas que expressam evento. Essas categorias devem fazer parte da entrada lexical dos verbos. Por exemplo, a informação semântica associada à entrada lexical de um verbo de evento pode exigir, permitir ou impedir a subespecificação [+ação]. No caso dos verbos intransitivos, parece que a categoria evento exige a subespecificação [+ação], enquanto verbos inacusativos que descrevem um evento permitem (e não exigem) tal subespecificação.

Com efeito, neste trabalho, estamos assumindo que a distribuição dos papéis temáticos pode ser fruto da composicionalidade dos itens lexicais que constituem uma sentença. Nessa direção, seria possível, então, dizer que o léxico contém apenas um verbo chegar, por exemplo (tratado aqui como um dos verbos da função GO), e a polissemia observada nas sentenças com esse tipo de verbo (como vimos acima) deve ser causada pelo fato de que o papel temático dessas sentenças é construído pela composição entre o verbo e o argumento por ele selecionado, ou seja, entre verbo e argumento interno. E a interpretação negativa ou positiva para o traço [+agente] de um sintagma parece ser um condicionador forte da posição que ele vai ocupar na sentença, como as evidências e resultados estatísticos acima ilustram.

\section{CONSIDERAÇÕES FINAIS}

A análise é favorável à nossa hipótese de que uma construção intransitiva privilegia a ordem NP V, enquanto a inacusatividade da construção caracteriza-se como o requisito fundamental de ocorrência da variação, ordem NP V e ordem V NP. Para explicar a variação no ambiente da inacusatividade, valemo-nos das discussões a respeito de uma análise composicional do conteúdo semântico dos itens lexicais que constituem a sentença, no caso específico, entre verbocomplemento. E os resultados estatísticos são evidências favoráveis à hipótese de que os condicionadores de natureza sintática e de natureza semântica mantêm entre si relações complexas e variadas, com respeito à ordem V NP, como por exemplo, na relação que se estabelece entre verbo inacusativo e argumento [-agentivo]. Mas, afinal, conjugado ao tipo categorial do verbo, agentividade é um traço do NP suficiente para determinar a ordem dos constituintes de uma construção inacusativa? Respostas a essas questões estão sendo discutidas a partir do cruzamento entre os fatores acima mencionados e aqueles que tratam da natureza do NP, em especial, dos traços semânticos de definitude e de especificidade. Objeto de discussão de um próximo trabalho. 
É importante destacar que este estudo faz parte de um trabalho mais amplo no sentido de tentar explicar talvez menos timidamente quais os contextos que favorecem a ordem V NP no português falado em Florianópolis. Entretanto, os resultados deste trabalho só contribuirão para a pesquisa científica se comparados a outros trabalhos variacionistas que investiguem (e que investigaram) a ordem $\mathrm{V}$ NP em outras regiões do Brasil. Tais resultados somados aos deste trabalho constituem, a nosso ver, apenas 'mais um passo' para a caracterização do fenômeno em estudo.

\section{BIBLIOGRAFIA}

BELLETTI, A. The case of unaccusatives. Linguistic Inquiry, v. 19, n. 1, p. 1-34, inverno 1988.

BERLINCK, R de A. A ordem $V N P$ no português do Brasil: sincronia e diacronia. Campinas, UNICAMP, 1988. Dissertação de mestrado.

, R. de A. La position du sujet en portugais: étude diachronique des variétés brésilienne et européene. Lovaina, Bélgica, Katholieke Universiteit Leuven, 1995. Tese de doutorado.

BURZIO, L. Italian Syntax. A Government-Binding Approch. Dordrecht, Reidel, 1986.

CHOMSKY, N. Lectures and Binding. Dordrecht, Foris, 1981.

_. N. Knowledge of language: its nature, origin and use. New York, Praeger, 1986.

COELHO, I. L. O caráter da posposição do SN em construções monoargumentais no português falado em Florianópolis. Trabalho apresentado no XIV Encontro Nacional da Associação Portuguesa de Lingüística. Aveiro, Portugal, 1998.

, I. L. A posposição do SN em construções monoargumentais: um caso de efeito de definitude? CD-ROOM do II Encontro do CELSUL. Florianópolis, 1999.

FIGUEIREDO SILVA, M. C. A posição sujeito no português brasileiro. Frases finitas e infinitivas. Campinas, SP, Ed. da UNICAMP, 1996.

JACKENDOFF, R. Toward an explanatory semantic representation. Linguistic Inquiry, v. 7, n. 1, p. 89-150, inverno, 1976.

, R. The status of thematic relations. Linguistic Inquiry, v. 18, n. 3, p. 369-411, verão, 1987.

KATO, M. \& TARALlO, F. The loss of VS syntax in Brazilian Portuguese. IN: KOCH, I. e SCHLIEBE-LANGE, B. (orgs). Linguistik in Brazilien. Tubingen, Niemeyer (no prelo)

KATO, M. et alli. Padrões de predicação no português falado no Brasil. IN: KATO, M. (org.) Gramática do Português Falado. v. V : Convergências. São Paulo, Campinas, FAPESP- Unicamp, 1996. 
KOOPMAN, H. e SPORTICHE, D. The position of subjects. Língua, v. 2, n. 1, p. 211-258, 1986.

LABOV, W. Sociolinguistic Patterns. Philadelphia, University of Pennsylvania Press, 1972.

LIRA, S. de. Subject postposition in Portuguese. D.E.L.T.A.. São Paulo, EDUC, v. 2, n. 1, 1986.

, S. de. The subject in Brazilian Portuguese. Nova York, Peter Lang, 1996.

PERLMUTTER, D. Evidence for subject downgrading in Portuguese. IN: J. Schmidt-Radefelt. Readings in Portuguese Linguistics. Amsterdam, NorthHolland Publishing Company, 1976.

VOTRE, S. J. \& NARO, A. Inversão do sujeito na fala carioca. Boletim da ABRALIN n. 6, p.189-196, 1984.

WHITAKER, R. F. As construções ergativas: um estudo semântico e sintático, Campinas, UNICAMP, 1989. Dissertação de mestrado.

ZILLES, A. M. S. A posposição do sujeito ao verbo no português falado no Rio Grande do Sul. II Congresso Nacional da ABRALIN. Florianópolis, UFSC, no período de 25 a 27 de fev. 1999. 